\title{
Accuracy of upper endoscopies with random biopsies to identify patients with gastric premalignant lesions who can safely be exempt from surveillance
}

\author{
Michiel C. Mommersteeg ${ }^{1}$ - Stella A. V. Nieuwenburg ${ }^{1} \cdot$ Wouter J. den Hollander $^{2}$ - Lisanne Holster ${ }^{1}$. \\ Caroline M. den Hoed ${ }^{1} \cdot$ Lisette G. Capelle $^{3}$. Tjon J. Tang ${ }^{4} \cdot$ Marie- Paule Anten $^{5}$ - Ingrid Prytz-Berset ${ }^{6}$. \\ Ellen M. Witteman ${ }^{7}$. Frank ter Borg ${ }^{8}$. Jordy P. W. Burger ${ }^{9} \cdot$ Michail Doukas $^{10} \cdot$ Marco J. Bruno $^{1}$. \\ Maikel P. Peppelenbosch ${ }^{1}$. Gwenny M. Fuhler ${ }^{1} \cdot$ Ernst J. Kuipers ${ }^{1} \cdot$ Manon C. W. Spaander $^{1} \mathbb{D}$
}

Received: 25 September 2020 / Accepted: 9 December 2020 / Published online: 22 February 2021

(c) The Author(s) 2021

\begin{abstract}
Introduction Guidelines recommend endoscopy with biopsies to stratify patients with gastric premalignant lesions (GPL) to high and low progression risk. High-risk patients are recommended to undergo surveillance. We aimed to assess the accuracy of guideline recommendations to identify low-risk patients, who can safely be discharged from surveillance.

Methods This study includes patients with GPL. Patients underwent at least two endoscopies with an interval of 1-6 years. Patients were defined 'low risk' if they fulfilled requirements for discharge, and 'high risk' if they fulfilled requirements for surveillance, according to European guidelines (MAPS-2012, updated MAPS-2019, BSG). Patients defined 'low risk' with progression of disease during follow-up (FU) were considered 'misclassified' as low risk.

Results 334 patients (median age 60 years IQR11; 48.7\% male) were included and followed for a median of 48 months. At baseline, 181/334 (54\%) patients were defined low risk. Of these, 32.6\% were 'misclassified', showing progression of disease during FU. If MAPS-2019 were followed, 169/334 (51\%) patients were defined low risk, of which 32.5\% were 'misclassified'. If BSG were followed, 174/334 (51\%) patients were defined low risk, of which 32.2\% were 'misclassified'. Seven patients developed gastric cancer (GC) or dysplasia, four patients were 'misclassified' based on MAPS-2012 and three on MAPS-2019 and BSG. By performing one additional endoscopy 72.9\% (95\% CI 62.4-83.3) of high-risk patients and all patients who developed GC or dysplasia were identified.

Conclusion One-third of patients that would have been discharged from GC surveillance, appeared to be 'misclassified' as low risk. One additional endoscopy will reduce this risk by $70 \%$.
\end{abstract}

Keywords Surveillance · Prevention · Gastric cancer · Atrophic gastritis · Intestinal metaplasia

$\begin{array}{ll}\text { Abbreviations } \\ \text { CAG } & \text { Chronic atrophic gastritis } \\ \text { GC } & \text { Gastric cancer } \\ \text { GPL } & \text { Gastric premalignant lesions } \\ \text { HGD } & \text { High-grade dysplasia } \\ \text { IM } & \text { Intestinal metaplasia } \\ \text { LGD } & \text { Low-grade dysplasia }\end{array}$

Michiel C. Mommersteeg and Stella A. V. Nieuwenburg contributed equally to this work.

Manon C. W. Spaander

v.spaander@erasmusmc.nl

Extended author information available on the last page of the article
MAPS Management of precancerous conditions and lesions in the stomach

BSG British society of gastroenterology

OLGIM Operative link on gastric intestinal metaplasia

\section{Introduction}

Prognosis of advanced gastric cancer is poor, with a fiveyear-survival rate of $20 \%$ [1]. However, if gastric cancer is detected at an early stage, survival rates improve up to 90\% [2, 3]. Chronic atrophic gastritis (CAG) and intestinal metaplasia (IM) are precursor lesions of gastric adenocarcinoma (GC) [4]. These premalignant lesions make gastric cancer suitable for screening and surveillance, depending 
on the regional prevalence of (pre-)malignant lesions and progression rates to cancer. Nationwide screening strategies are mainly relevant for high-GC prevalence regions such as East-Asia, where population-based screening programs are implemented [5]. In case advanced premalignant lesions are detected, patients are eligible for surveillance and early intervention when possible [6]. For regions with low prevalence rates, such as Western Europe and North America, nationwide screening is not recommended due to a low a priori risk. However, when patients of these regions are inadvertently diagnosed with advanced premalignant lesions, for instance, during routine endoscopy, surveillance should be considered given the risk of progression to cancer. The debate about the balance between harms and benefits of surveillance strategies is still ongoing [7]. To this end, US guidelines state that surveillance is not indicated except for individuals with a known increased gastric cancer risk, such as persons of Asian ancestry or patients with a positive family history [8]. European MAPS (management of epithelial precancerous conditions and lesions in the stomach) as well as the British guidelines, recommend surveillance in patients with a premalignant gastric lesion [9-11]. These surveillance recommendations depend on the extent and severity of these premalignant lesions. The MAPS-2012 guideline recommended surveillance for patients with extensive CAG or IM. In the updated MAPS-2019 guideline, surveillance was extended to patients with CAG and IM limited to either the antrum or the corpus and presence of incomplete intestinal metaplasia (in any of the biopsies), autoimmune gastritis, persistent Helicobacter pylori (H. pylori) infection or a first degree relative with gastric cancer. In 2019, the British Society of Gastroenterology also published a guideline (BSG) on the management of gastric premalignant lesions. The recommendations on surveillance of premalignant lesions were mostly identical to the revised MAPS-2019 guideline. The only difference with the MAPS guideline is that patients with autoimmune gastritis and CAG or IM limited to the antrum or corpus were not referred for further surveillance.

To assess the extent and severity of premalignant gastric lesions, endoscopic surveillance is advised. However, endoscopic recognition of gastric premalignant lesions can be difficult. Therefore, obtaining random biopsies throughout the stomach according to the updated Sydney protocol is recommended [12]. Nevertheless, due to the uneven distribution of gastric premalignant lesions, random biopsies may not properly reflect the extent of the lesions and subsequently the individual gastric cancer risk [13]. Since only a few patients will develop gastric cancer, it is essential that surveillance strategies in practice lead to the identification of those few cases. While the addition of new risk factors to the MAPS-2019 and BSG potentially allows better stratification of at-risk patients, thus far, there is only limited data describing to what extent we can accurately dismiss patients with premalignant gastric lesions from surveillance, based on their low risk of gastric cancer development. The aim of this study was to assess to what extent we can accurately identify low-risk patients who can safely be discharged from gastric surveillance according to the recommendations of MAPS-2012, MAPS-2019 and BSG guideline.

\section{Methods}

\section{Study design}

This study is based on the Proregal study (Progression and Regression of precancerous Gastric Lesions). The design of the study has been described previously [14]. In short, this study was initiated in 2009 and is an ongoing prospective cohort study carried out in six hospitals (one academic, five regional) in the Netherlands and one regional hospital in Norway. Patients are eligible for inclusion if they are over 18 years of age and diagnosed with one of the following conditions at routine endoscopy (t0): atrophic gastritis, intestinal metaplasia and/or dysplasia in any part of the gastric mucosa. Patients are excluded from participation if they have: (1) previously undergone upper gastrointestinal surgery, (2) a previous diagnosis of gastric carcinoma, or any other malignancy not being in remission, (3) severe comorbidity limiting their expected survival to less than 2 years, (4) portal hypertension, or (5) a proven $\mathrm{CDH1}$ mutation. In case $H$. pylori was present, $H$. pylori eradication was provided, and eradication was verified. in all patients (20 patients had persistent $H$. pylori colonization). H. pylori eradication was eventually achieved in all patients.

In all subjects, a surveillance endoscopy is performed at one (t1) and three ( $\mathrm{t} 2)$ years after the initial endoscopy. Random biopsy samples are obtained according to the Proregal biopsy protocol with targeted biopsies in case of visible gastric lesions (Fig. 1).

In case of low-grade dysplasia (LGD) or high-grade dysplasia (HGD), the surveillance interval is shortened to twelve and six months, respectively. In case a visible lesion is detected, endoscopic resection of the lesion is performed. After $\mathrm{t} 2$, continuation or cessation of surveillance is decided based on the recommendations of the MAPS guideline. For the purpose of this study, subjects who were discharged from further surveillance based on the MAPS guideline recommendation at $\mathrm{t} 2$ were re-invited for endoscopy $(\mathrm{t} 3)$.

\section{Patient selection}

All patients from the Proregal cohort were eligible for inclusion provided patients had at least one follow-up 


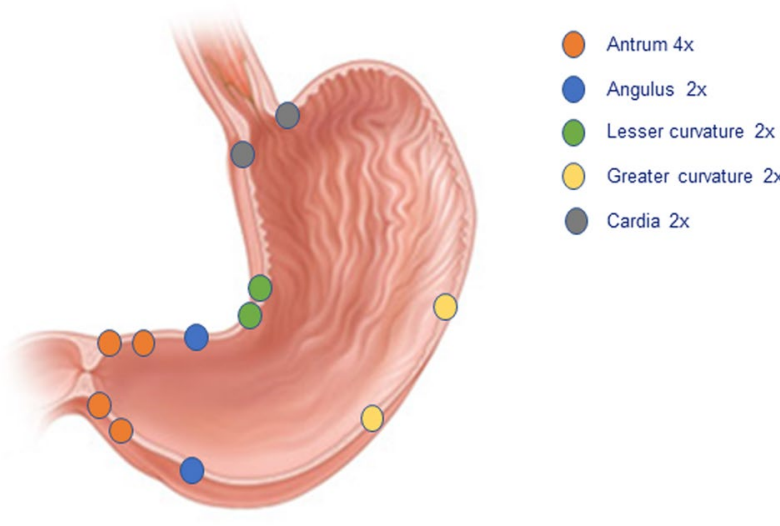

Fig. 1 Locations of standardised random gastric biopsies obtained during endoscopy for this study

endoscopy. Patients were classified as low or high risk. Low-risk patients were defined as patients with premalignant gastric lesions, who do not fulfil the requirements for surveillance (i.e. IM limited to the antrum). 'High risk' patients are patients with premalignant gastric lesions who are advised to undergo surveillance (i.e. IM in both antrum and corpus). Requirements for surveillance are described in more detail in Supplementary Table 1.

At baseline, patients were defined as 'low risk' for progression of disease if they fulfilled requirements for discharge based on the European guidelines MAPS-2012, MAPS-2019 or the BSG guideline. Patients were defined as 'high risk' if further surveillance was indicated according to these guidelines.

To assess the safety of discharging patients from further surveillance based on MAPS/BSG guideline recommendations, we included the 'low risk' patients who had no indication for further surveillance according to the guidelines at $\mathrm{t} 1 \mathrm{or} \mathrm{t} 2$ (e.g. limited extension of IM), but underwent a surveillance endoscopy within the scope of this study. We correlated the findings with the outcome of the endoscopy performed at $\mathrm{t} 2$ and $\mathrm{t} 3$, respectively. In case lesions were found at the follow-up endoscopy for which surveillance is recommended, the patient was defined as 'misclassified' as low risk for gastric cancer development.

Furthermore, we linked all patients to the Netherlands Cancer Registry, managed by the Netherlands Comprehensive Cancer Organisation (IKNL) to account for all (interval) gastric cancers even after surveillance was stopped. Since 1989, the Netherlands Cancer Registry registers all participants diagnosed with cancer in the Netherlands. The study design is depicted in Fig. 2. The study protocol was approved by the Institutional Review Board (MEC-2009-090).

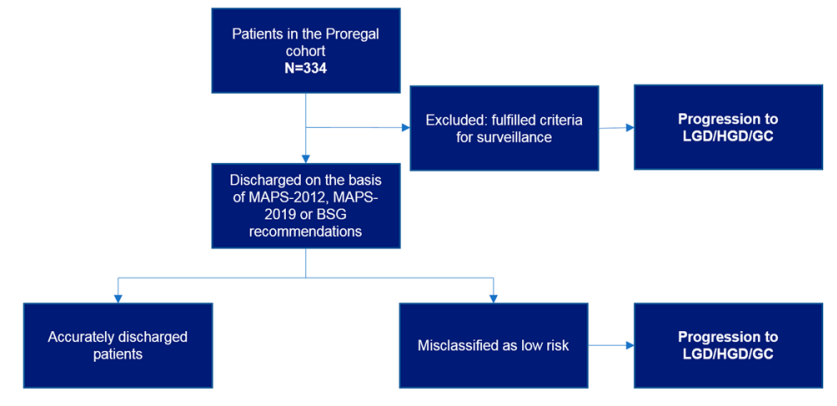

Fig. 2 Flowchart of the study design. $G C$ gastric cancer; $H G D$ highgrade dysplasia; $L G D$ low-grade dysplasia; MAPS management of precancerous conditions and lesions in the stomach; Proregal progression and regression of precancerous lesions

\section{MAPS-2012}

The MAPS guideline recommendations were first published in 2012 [9]. Chronic atrophic gastritis (CAG) or intestinal metaplasia (IM) confined to the antrum did not require further surveillance. CAG or IM in both antrum and corpus or only in the corpus required endoscopic surveillance every three years (Suppl. Table 1).

\section{MAPS-2019}

The MAPS guideline recommendations were updated in 2019 [10]. CAG or IM limited to the antrum or corpus does not require further surveillance. However, surveillance every three years is recommended if the subject meets one of the following criteria: first degree family history of gastric cancer, autoimmune gastritis, persistent $H$. pylori infection or incomplete IM (Table 1). Surveillance every $1-2$ years is recommended in case of a first degree relative with GC (Suppl. Table 1).

\section{BSG}

The BSG guideline recommendations were published in 2019 [11]. In this guideline, CAG or IM limited to the antrum or corpus does not require further surveillance. However, surveillance every three years is recommended if the subject meets one of the following criteria: first degree family history of gastric cancer or persistent $H$. pylori infection (Table 1).

\section{Statistical analyses}

Baseline characteristics are presented as mean with standard deviation (SD) or median with interquartile range (IQR) when appropriate. Kaplan-Meier curves were performed on the proportion of patients identified as still at risk after 
Table 1 Baseline characteristics of the total Proregal cohort

\begin{tabular}{ll}
\hline & $\begin{array}{l}\text { Proregal } \\
\text { cohort } \\
(n=334)\end{array}$ \\
\hline Gender (male, \%) & 48.7 \\
Age (median, IQR) & $60(11)$ \\
H. pylori positive (histology) & $103(31)$ \\
Follow-up months (median, IQR) & $48(24)$ \\
Most severe lesion recent endoscopy & \\
OLGIM 0 & $123(36)$ \\
OLGIM I & $55(16)$ \\
OLGIM II & $81(24)$ \\
OLGIM III & $51(15)$ \\
OLGIM IV & $9(3)$ \\
Lesions requiring treatment & \\
LGD & 1 \\
HGD & 2 \\
GC & 4 \\
High-risk features & \\
Persistent $H$. pylori infection & 20 \\
Autoimmune gastritis & 20 \\
First degree family history of GC & 47 \\
\hline
\end{tabular}

H. pylori Helicobacter pylori; IQR inter quartile range; $G C$ gastric cancer; $H G D$ high-grade dysplasia; $L G D$ low-grade dysplasia; OLGIM operative link on gastric intestinal metaplasia assessment; Proregal cohort total number of the prospective cohort that are or have been under surveillance for their gastric premalignant lesions

${ }^{\mathrm{a} C}$ Capelle et al., Gastrointest Endosc., 2010 [31]

(supposed) discharge of surveillance per year and per endoscopy for MAPS-2012, MAPS-2019 and BSG guidelines.The analyses were performed using SPSS v.24 statistical package (SPSS Inc, Chicago, IL).

\section{Results}

\section{Patient characteristics}

In total, 334 patients were included. Median age was 60 years (IQR 11) and $48.7 \%$ were men. This cohort captured seven cases of dysplasia or gastric cancer. Baseline characteristics of the entire cohort are shown in Table 1 and were described in more detail previously [14].

\section{Following the MAPS-2012 guideline recommendation}

At baseline, 153/334 (45.8\%) patients were correctly defined as high risk (i.e. already fulfilled the criteria for surveillance according to the guideline) and therefore excluded. Of the remaining 181 low-risk patients (i.e. would have been discharged from further surveillance according to the guideline), 59 patients (32.6\%) were misclassified as low risk because they had gastric lesions at subsequent endoscopies that gave reason to continue surveillance (i.e. gastric premalignant lesions not limited to the antrum) see also Fig. 3a. This included four out of the total seven cases of LGD/HGD/gastric cancer cases. LGD was found in one patient, HGD was found in two patients, and one patient developed gastric cancer. One of the patients with HGD underwent endoscopic resection and died from causes unrelated to gastric cancer or the procedure. The other patient with HGD underwent a successful gastrectomy. The patient with gastric cancer and the patient with LGD underwent an endoscopic resection and are currently in remission for over two years. Patient characteristics of these cases are available in Table 2.

\section{Following the MAPS-2019 guideline recommendation}

At baseline, 165/334 (49.4\%) patients were correctly defined as high risk (i.e. already fulfilled the criteria for surveillance according to the guideline) and therefore excluded. Of the remaining 169 low-risk patients (i.e. would have been discharged from further surveillance according to the guideline), 55 patients (32.5\%) were misclassified as low risk because they had gastric lesions at subsequent endoscopies that gave reason to continue surveillance (i.e. gastric premalignant lesions not limited to the antrum). This included three out of the total seven cases of LGD/HGD/gastric cancer (one case of LGD, HGD and gastric cancer each) see also Fig. 3b. These patients were also misclassified by the MAPS-2012 guideline. The correctly classified patient with HGD (that was misclassified in MAPS-2012) was included for surveillance according to MAPS-2019 because of a first degree relative with gastric cancer. This patient had HGD, but declined further therapy due to comorbidities and age, although (endoscopic) resection might have been possible. Another patient with carcinoma who would have been discharged according to the extent of his lesions (limited to the corpus) was recommended to undergo surveillance according to the MAPS-2019 guideline, also because of a first degree relative with gastric cancer. Patient characteristics of these cases are depicted in Table 2.

\section{Following the BSG guideline recommendation}

At baseline, 160/334 (47.9\%) patients were correctly defined as high risk (i.e. already fulfilled the criteria for surveillance according to the guideline) and therefore excluded. Of the remaining 174 low-risk patients (i.e. would have 
Table 2 Characteristics of patients identified with a resectable lesion in the complete proregal cohort including which guideline would have accurately identified these patients being at risk

\begin{tabular}{|c|c|c|c|c|c|c|c|c|c|}
\hline \# & Age diagnosis & Gender & $\begin{array}{l}\text { First } \\
\text { diagnosis } \\
\text { of GPL }\end{array}$ & $\begin{array}{l}\text { Guideline } \\
\text { recommending } \\
\text { surveillance }\end{array}$ & $\begin{array}{l}\text { Lesions at end } \\
\text { of surveillance }\end{array}$ & $\begin{array}{l}\text { High-risk } \\
\text { feature(s) }\end{array}$ & $\begin{array}{l}\text { OLGIM } \\
\text { (most } \\
\text { severe) }\end{array}$ & $\begin{array}{l}\text { Lesion found in } \\
\text { follow-up }\end{array}$ & Therapy \\
\hline 1 & $78^{\mathrm{a}}$ & Male & 1996 & None & $\begin{array}{l}\text { Moderate } \\
\text { intestinal } \\
\text { metaplasia of } \\
\text { antrum and } \\
\text { angulus }\end{array}$ & None & III & $\begin{array}{l}\text { High-grade dys- } \\
\text { plasia antrum }\end{array}$ & $\begin{array}{l}\text { Endoscopic } \\
\text { resection }\end{array}$ \\
\hline 2 & 57 & Male & 2010 & None & $\begin{array}{l}\text { Moderate } \\
\text { intestinal } \\
\text { metaplasia of } \\
\text { antrum and } \\
\text { angulus }\end{array}$ & None & IV & $\begin{array}{l}\text { Intestinal-type } \\
\text { adenocarci- } \\
\text { noma angulus }\end{array}$ & $\begin{array}{l}\text { Endoscopic } \\
\text { resection }\end{array}$ \\
\hline 3 & 64 & Female & 2009 & None & $\begin{array}{l}\text { Slight intestinal } \\
\text { metaplasia of } \\
\text { the antrum }\end{array}$ & None & III & $\begin{array}{l}\text { Low-grade } \\
\text { dysplasia of } \\
\text { the antrum }\end{array}$ & $\begin{array}{l}\text { Endoscopic } \\
\text { resection }\end{array}$ \\
\hline 4 & 77 & Male & 1996 & $\begin{array}{l}\text { MAPS-2019 } \\
\text { BSG }\end{array}$ & $\begin{array}{l}\text { Chronic gastri- } \\
\text { tis of antrum } \\
\text { and corpus }\end{array}$ & $\begin{array}{l}\text { First degree } \\
\text { family with } \\
\text { GC, AI gas- } \\
\text { tritis }\end{array}$ & IV & $\begin{array}{l}\text { High-grade } \\
\text { dysplasia of } \\
\text { the antrum }\end{array}$ & No therapy \\
\hline 5 & 46 & Male & 2008 & $\begin{array}{l}\text { MAPS-2019 } \\
\text { MAPS-2012 } \\
\text { BSG }\end{array}$ & N/A & $\begin{array}{l}\text { First degree } \\
\text { family with } \\
\text { GC }\end{array}$ & II & $\begin{array}{l}\text { Intestinal-type } \\
\text { adenocarci- } \\
\text { noma antrum }\end{array}$ & $\begin{array}{l}\text { Endoscopic } \\
\text { resection }\end{array}$ \\
\hline 6 & 53 & Female & 2009 & $\begin{array}{l}\text { MAPS-2012 } \\
\text { MAPS-2019 } \\
\text { BSG }\end{array}$ & N/A & $\begin{array}{l}\text { First degree } \\
\text { family with } \\
\text { GC }\end{array}$ & III & $\begin{array}{l}\text { Diffuse-type } \\
\text { gastric cancer }\end{array}$ & Total gastrectomy \\
\hline 7 & $72^{\mathrm{a}}$ & Male & 2006 & $\begin{array}{l}\text { MAPS-2012 } \\
\text { MAPS-2019 } \\
\text { BSG }\end{array}$ & N/A & None & IV & $\begin{array}{l}\text { Intestinal-type } \\
\text { adenocarci- } \\
\text { noma } \\
\text { Lesser curva- } \\
\text { ture/angulus }\end{array}$ & Total gastrectomy \\
\hline
\end{tabular}

GPL gastric premalignant lesion; MAPS management of precancerous conditions and lesions in the stomach; $B S G$ British society of Gastroenterology guideline; N/A not applicable; $G C$ gastric cancer; $A I$ autoimmune

${ }^{\text {a }}$ Patient is deceased

been discharged from further surveillance according to the guideline), 56 patients (32.2\%) were misclassified as low risk because they had gastric lesions at subsequent endoscopies that gave reason to continue surveillance (i.e. gastric premalignant lesions not limited to the antrum). This included three out of the total seven cases of LGD/HGD/ gastric cancer (one case of LGD, HGD and gastric cancer each) see also Fig. 3c. These patients were also misclassified by the MAPS-2012 and MAPS-2019 guideline. The correctly classified HGD patient (who was misclassified in MAPS-2012) was included for surveillance according to BSG because of a first degree relative with gastric cancer. This patient had HGD, but declined further therapy due to comorbidities and age, although (endoscopic) resection might have been possible. Another patient with carcinoma who would have been discharged according to the extent of his lesions (limited to the corpus) was recommended to undergo surveillance according to the BSG guideline, also because of a first degree relative with gastric cancer. Patient characteristics of these cases are depicted in Table 2.

\section{Longitudinal follow-up}

Figure 4 shows a graphical presentation of the results of each endoscopy according to the MAPS-2019 guideline. As can be appreciated from this figure, several patients continuously switch between high and low risk of progression. The number of endoscopies or time necessary to correctly identify low-risk patients was visualized by a Kaplan-Meier curve. As seen in Fig. 5a, c, e, one additional endoscopy identifies over $75.4 \%$ (95\% CI 64.3-86.6), 72.9\% (95\% CI 62.4-83.3) and $73.2 \%$ (95\% CI 59.7-84.2) of high-risk patients according to the MAPS-2012, MAPS-2019 or BSG guideline, respectively. After two additional endoscopies, this percentage increases to $89.5 \%$ (95\% CI 81.5-97.5), $85.7 \%$ (95\% CI 77.5-93.9) and 85.7 (95\% CI 73.8-93.6 or 
a

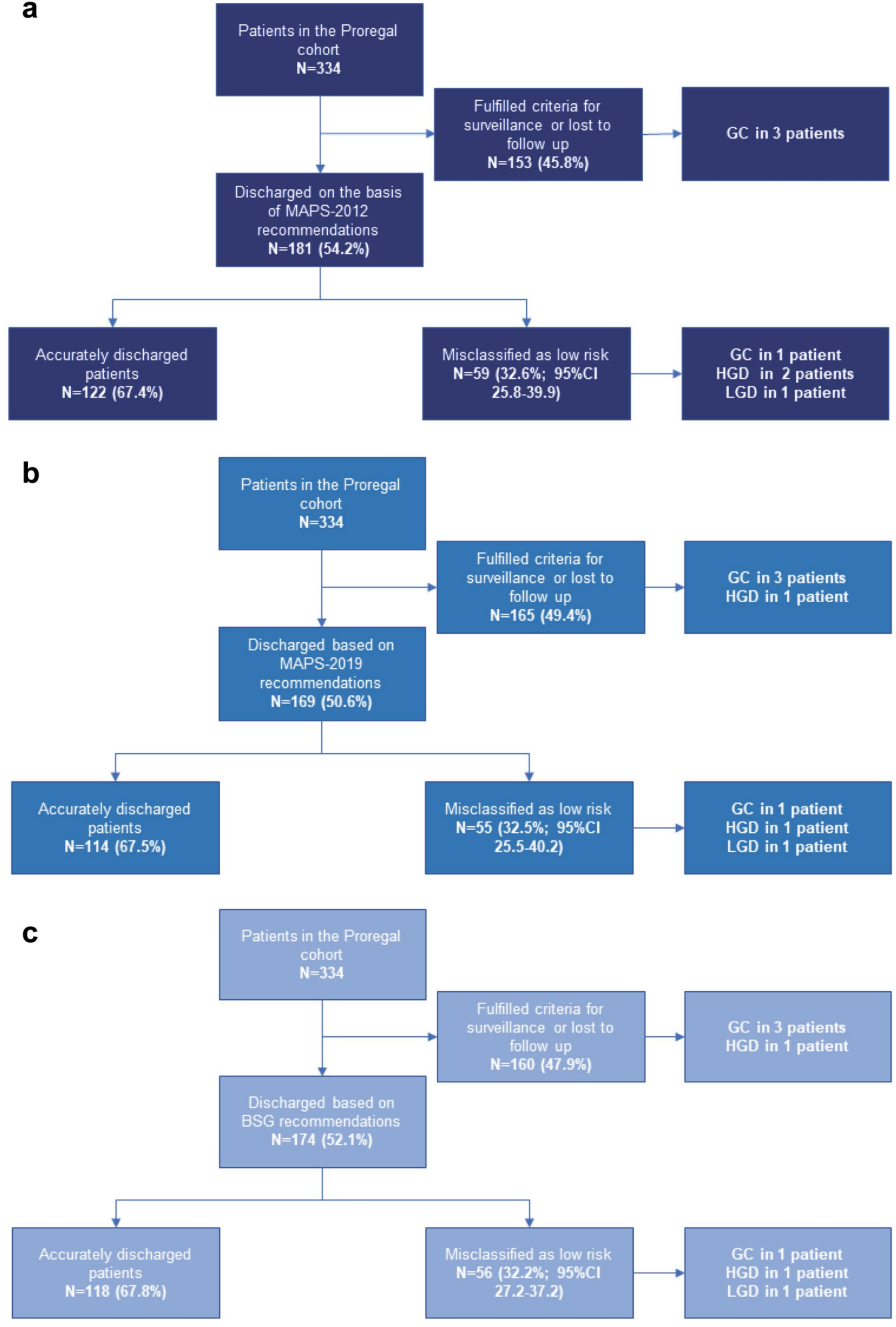


4Fig. 3 Schematic visualization of surveillance of patients with premalignant gastric lesion according to the MAPS-2012 guideline (a), according to the MAPS-2019 guideline (b) and according to the BSG (c). $L G D$ low-grade dysplasia; $H G D$ high-grade dysplasia; $G C$ gastric cancer; $C I$ confidence interval; $M A P S$ management of precancerous conditions and lesions in the stomach; Proregal progression and regression of precancerous lesions

BSG, respectively. Figure 5b, d, f shows patients who were defined as low risk according to MAPS-2012, MAPS-2019 or BSG by years of follow-up. After 3 years, the percentage of correctly identified patients at low gastric cancer development risk is $77.2 \%$ (95\% CI 66.3-88.1), 80.9\% (95\% CI 74.1-91.7) and $80.4 \%$ (95\% CI 67.6-89.8) as shown in Fig. 5b, d, f. In this period, all patients underwent either one or two additional endoscopies. All of the misclassified low-risk patients, who were diagnosed with GC or dysplasia during follow-up, would have been correctly classified as high risk in case one additional endoscopy between two and four years was performed (following any guideline).

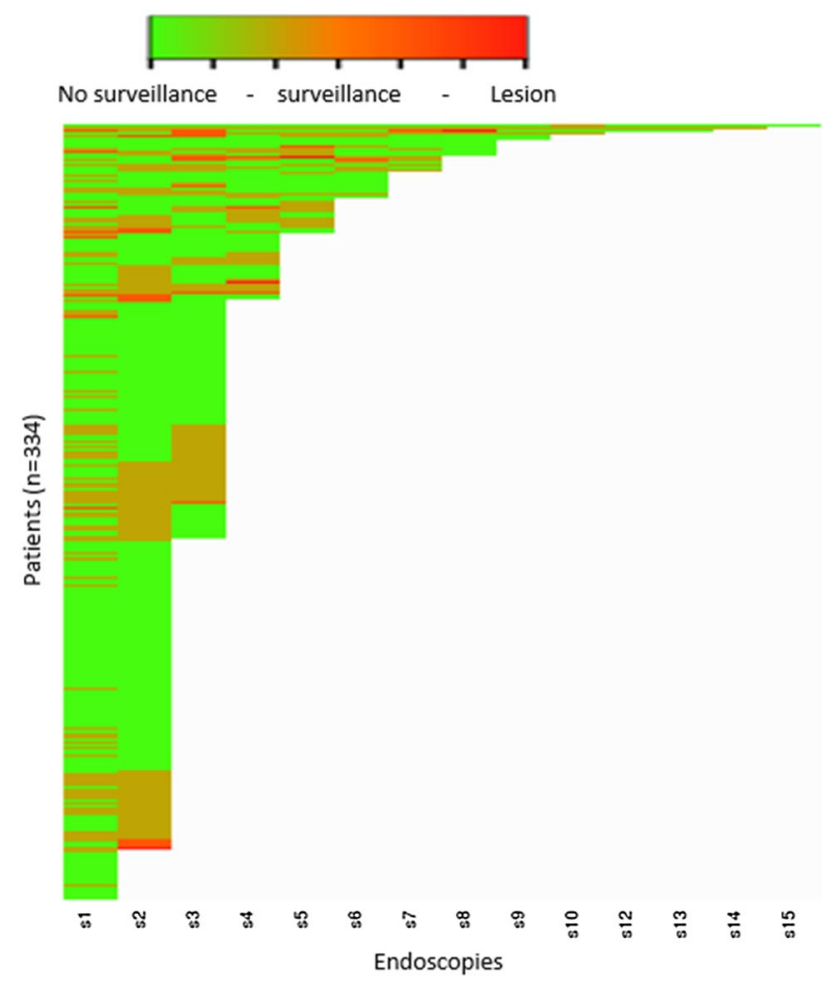

Fig. 4 Heat map of the outcomes of the PROREGAL study, based on MAPS-2019 guideline. On the $Y$-axis, all individual patients have been plotted, on the $X$-axis, the endoscopies are shown. A green colour indicates that MAPS-2019 would not recommend an endoscopy, an orange colour represents a recommendation of surveillance. A red colour represents detection of lesions that should be considered for (endoscopic) resection (i.e. LGD, HGD, gastric adenocarcinoma). Several patients who would have been discharged based on the lesion found and according to MAPS-2019 guideline did show lesions warranting surveillance in subsequent endoscopies

\section{Discussion}

To the best of our knowledge, this is the first study that evaluates how accurate we can identify low-risk GPL patients, and whether they can be safely discharged from further surveillance based on guideline recommendations. Due to the addition of several risk factors in MAPS-2019 and BSG as compared to MAPS-2012, MAPS-2019 and BSG improve the identification of high-risk patients who develop lesions requiring treatment, while reducing the amount of patients under surveillance. Nevertheless, a large proportion of patients at risk of neoplastic progression are still missed. Up to $32 \%$ of patients who are discharged from gastric cancer surveillance appeared to be misclassified as 'low risk' on subsequent endoscopy, including three out of the total of seven HGD/GC cases following the current European guidelines (MAPS-2019 and BSG). By adding one additional endoscopy, all patients who developed dysplasia or cancer were correctly identified as high risk and risk of misclassification was reduced by $72.9 \%$. Dismissing patients from further surveillance after two 'negative' endoscopies is already common practice in colonic polyp surveillance and might be considered in the setting of gastric premalignant lesions [15].

Currently, extension and severity of gastric premalignant lesions are determined by upper endoscopy with random biopsies. This might cause sampling error and with that, underestimation of the true extent of lesions [16, 17]. This could explain the number of patients who were misclassified as low risk in our study, based on the subsequent endoscopy results. It has been described previously that conventional white light endoscopy (WLE) findings do not correlate well to histological findings in gastric premalignant lesions [18, 19]. Advanced endoscopic techniques such as high-definition endoscopes and imaging enhancement technologies have improved markedly in the past years [20, 21]. HighDefinition-White Light Endoscopy (HD-WLE) has improved the correlation between endoscopic and histological diagnosis, with a sensitivity ranging between $75 \%$ and $92.7 \%$ and a specificity ranging between $92.7 \%$ and $100 \%$ [20, 21]. However, when measured in daily clinical practice, this accuracy decreases to $53 \%$ sensitivity and $98 \%$ specificity [22]. The addition of Narrow band imaging (NBI) to high-resolution endoscopy can further enhance accuracy up to a sensitivity of $85 \%$ and a specificity of $77 \%$ [23]. Our study highlights the importance of embracing and further investigating endoscopic improvement tools to stratify at-risk individuals with better accuracy and make surveillance guidelines more efficient [23]. These improvements in endoscopic techniques opens possibilities for targeted biopsies during surveillance endoscopies, which is expected to lower sampling error. On the other hand, improvements in endoscopic techniques will 

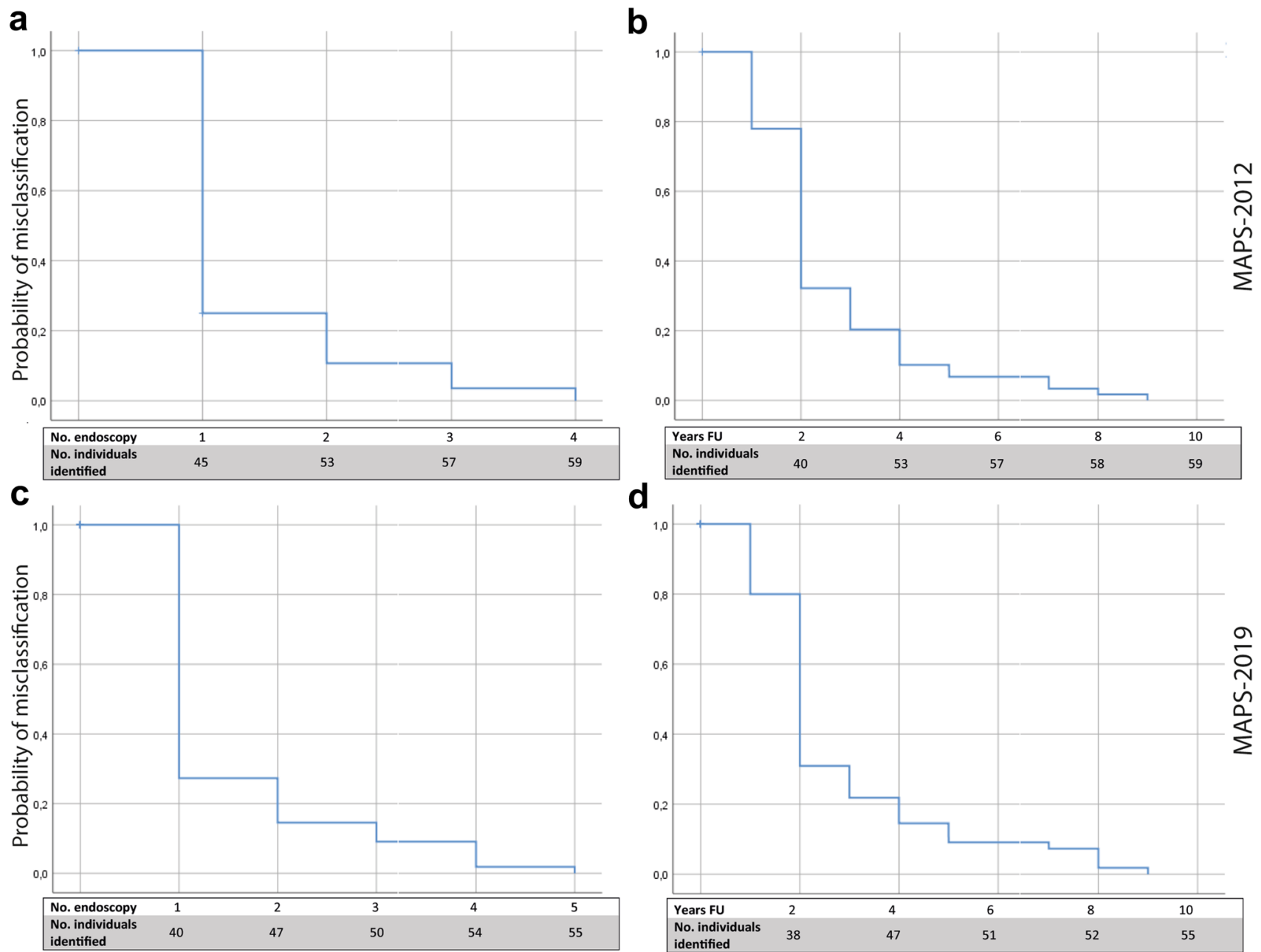

d
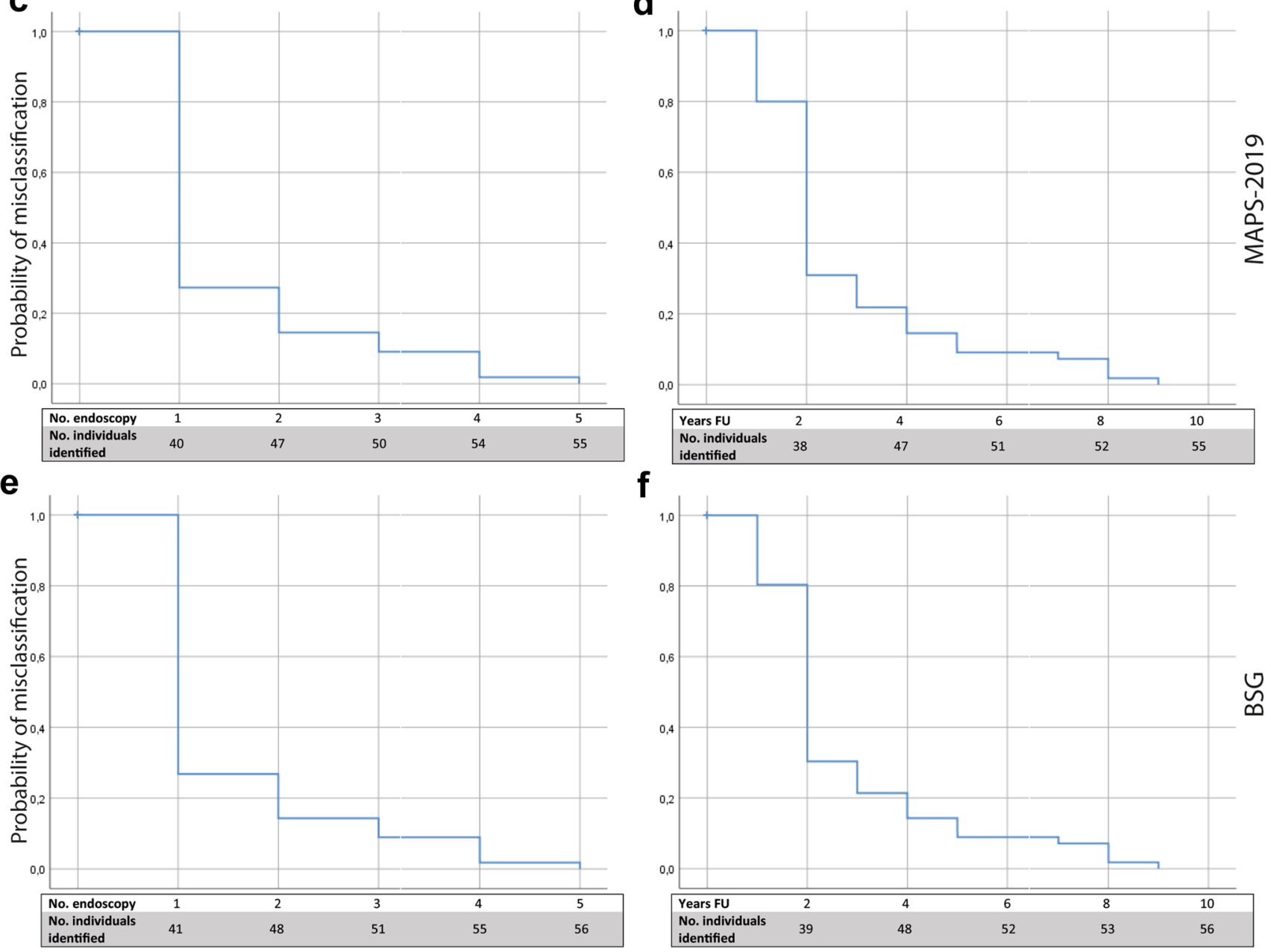

f

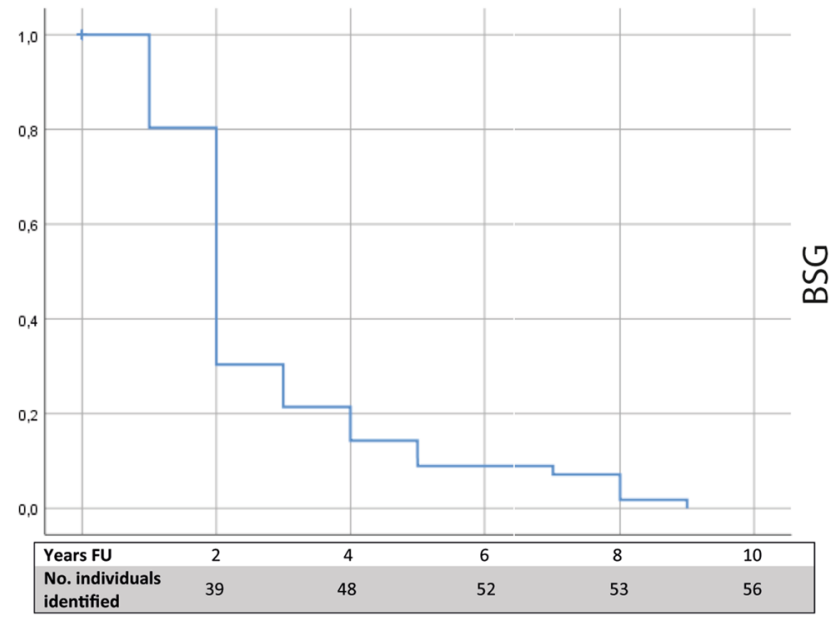

Fig. 5 Kaplan-Meier analysis of the probability of patients being misclassified as low risk for gastric cancer. a Patients who were misclassified as low risk according to MAPS-2012, distinguished by number of endoscopies needed until identified as still at risk. b Patients who were misclassified as low risk according to MAPS2012, distinguished by years of follow-up until identified as still at risk. c Patients who were misclassified as low risk according to MAPS-2019, distinguished by number of endoscopies needed until

identified as still at risk. d Patients who were misclassified as low risk according to MAPS-2019, distinguished by years of follow-up until identified as still at risk. e Patients who were misclassified as low risk according to BSG, distinguished by number of endoscopies needed until identified as still at risk. f Patients who were misclassified as low risk according to BSG, distinguished by years of follow-up until identified as still at risk. No. number of; $F U$ follow-up; MAPS management of precancerous conditions and lesions in the stomach 
only lead to a decrease in sampling error if endoscopist is trained to correctly interpret endoscopic images and identify the gastric lesions. MAPS-2019 guidelines recommend the use of NBI or chromoendoscopy as it outperforms the use of WLE alone as described above. However, the use of other virtual chromoendoscopy such as i-Scan or FICE is less well investigated. These new developments may contribute to a better detection of premalignant gastric lesions, but therefore further research is necessary, especially to assess the usability and yield in daily practice in non-expert hands before recommendations can be made.

Another potential explanation for the apparent changes in perceived severity of lesions during follow-up is that it represents regression of lesions, rather than sampling error. $H$. pylori eradication effectively blocks progression of intestinal metaplasia and reduces the risk of gastric cancer [24]. While regression of (chronic) atrophic gastritis has been suggested [25-27], actual regression or disappearance of IM has only been described in several individual studies. Indeed, several meta-analyses show no significant regression of IM even after $H$. pylori eradication and long-term treatment with a Cox 2 inhibitor [28, 29]. This held true for premalignant lesions in all the different locations of the stomach and supports the idea that sampling error contributes more to the fluctuating severity of lesions in our cohort than biological pro- or regression of disease [29, 30]. This raises the question whether histology from the last available endoscopy only is sufficient to identify patients who are at risk for gastric cancer development. According to our data, performing one additional endoscopy will identify the majority of patients who otherwise would have been inappropriately discharged. A surveillance strategy in which longitudinal data of all previous endoscopies are taken into account in risk assessment should be a future step.

The main challenge of surveillance strategies, especially in low-risk areas, is to identify the small proportion of patients that will benefit from surveillance while circumventing the burdens of such strategy. No surveillance strategy will perfectly identify all patients at risk. Therefore, it is important to take into account the risk of progression of premalignant lesions, the availability of a relatively safe and effective method to treat (early) cancers and the burden due to surveillance for both patient as well as health care. In three $(43 \%)$ out of the seven patients who developed gastric cancer or dysplasia, at least one high-risk feature was present. Our study shows that the addition of risk factors (autoimmune gastritis, first degree family history and persistent $H$. pylori infection) in MAPS-2019 and BSG indeed increases the yield of the current surveillance strategy and highlights the importance of continuing this improvement of risk stratification.
Several limitations have to be taken into account. First, this is an observational study which is not powered to make specific recommendations to improve current guidelines. This study solely provides descriptive information. Larger sample size in a randomized controlled trial setting would be needed to truly investigate the risk of misclassification and improve on guideline recommendations regarding biopsy strategies and surveillance (intervals). Furthermore, misclassification of patients is unavoidable and what percentage is deemed acceptable is debatable. This will depend on the costs health systems are willing to bear. Also, even though (almost) half of the dysplasia/gastric cancer cases in our cohort would never have received a surveillance endoscopy if guidelines were followed, these patients may have presented themselves when complaints would have arisen. Inevitably, this would have caused some delay in their treatment. However, the possibility of endoscopic treatment and outcome can only be speculated upon.

In conclusion, cancer detection improved with the updated MAPS-2019 and BSG guidelines, however, still three out of seven dysplasia/GC cases were missed. Furthermore, one-third of patients were misclassified as low risk for gastric cancer development and therefore would have inappropriately been discharged from further surveillance. The majority of these patients could be identified by performing one additional endoscopy within three years. Our study emphasizes the need for further improvement of stratifying at-risk individuals and improved endoscopic recognition of premalignant gastric lesions.

Supplementary Information The online version contains supplementary material available at https://doi.org/10.1007/s10120-020-01149-2.

Acknowledgements This study has been supported by the UEG research price.

\section{Compliance with ethical standards}

Conflict of interest MCM declares that he has no conflict of interest. SAVN declares that she has no conflict of interest. WJH declares that he has no conflict of interest. LH declares that she has no conflict of interest. CMH declares that she has no conflict of interest. LGC declares that she has no conflict of interest. TJT declares that he has no conflict of interest. MPA declares that she has no conflict of interest. IPB declares that she has no conflict of interest. EMW declares that she has no conflict of interest. FTB declares that he has no conflict of interest. JPWB declares that he has no conflict of interest. MD declares that he has no conflict of interest. MJB has received research grants from from Boston Scientific, grants and personal fees from Cook Medical, grants from Pentax Medical, grants from 3M, grants from Mylan, grants from InterScope, outside the submitted work;. MPP declares that he has no conflict of interest. GMF declares that she has no conflict of interest. EJK declares that he has no conflict of interest. MCWS declares that she has no conflict of interest. 
Ethical approval All procedures performed in studies involving human participants were in accordance with the ethical standards of the institutional and/or national research committee and with the 1964 Helsinki declaration and its later amendments or comparable ethical standards. This article does not contain any studies with animals performed by any of the authors.

Informed consent Informed consent was obtained from all individual participants included in the study.

Open Access This article is licensed under a Creative Commons Attribution 4.0 International License, which permits use, sharing, adaptation, distribution and reproduction in any medium or format, as long as you give appropriate credit to the original author(s) and the source, provide a link to the Creative Commons licence, and indicate if changes were made. The images or other third party material in this article are included in the article's Creative Commons licence, unless indicated otherwise in a credit line to the material. If material is not included in the article's Creative Commons licence and your intended use is not permitted by statutory regulation or exceeds the permitted use, you will need to obtain permission directly from the copyright holder. To view a copy of this licence, visit http://creativecommons.org/licenses/by/4.0/.

\section{References}

1. Sun F, Sun H, Mo X, Tang J, Liao Y, Wang S, et al. Increased survival rates in gastric cancer, with a narrowing gender gap and widening socioeconomic status gap: a period analysis from 1984 to 2013. J GastroenterolHepatol. 2018;33(4):837-46.

2. Everett SM, Axon AT. Early gastric cancer in Europe. Gut. 1997;41(2):142-50.

3. Matsuda T, Saika K. The 5-year relative survival rate of stomach cancer in the USA, Europe and Japan. Jpn J ClinOncol. 2013;43(11):1157-8.

4. Correa P, Haenszel W, Cuello C, Tannenbaum S, Archer M. A model for gastric cancer epidemiology. Lancet. 1975;2(7924):58-60.

5. Fock KM, Talley N, Moayyedi P, Hunt R, Azuma T, Sugano K, et al. Asia-Pacific consensus guidelines on gastric cancer prevention. J GastroenterolHepatol. 2008;23(3):351-65.

6. Sugano K, Tack J, Kuipers EJ, Graham DY, El-Omar EM, Miura $\mathrm{S}$, et al. Kyoto global consensus report on Helicobacter pylori gastritis. Gut. 2015;64(9):1353-67.

7. de Vries AC, van Grieken NC, Looman CW, Casparie MK, de Vries E, Meijer GA, et al. Gastric cancer risk in patients with premalignant gastric lesions: a nationwide cohort study in the Netherlands. Gastroenterology. 2008;134(4):945-52.

8. Committee ASoP, Evans JA, Chandrasekhara V, Chathadi KV, Decker GA, Early DS, et al. The role of endoscopy in the management of premalignant and malignant conditions of the stomach. GastrointestEndosc. 2015;82(1):1-8.

9. Dinis-Ribeiro M, Areia M, de Vries AC, Marcos-Pinto R, Monteiro-Soares M, O'Connor A, et al. Management of precancerous conditions and lesions in the stomach (MAPS): guideline from the European Society of Gastrointestinal Endoscopy (ESGE), European Helicobacter Study Group (EHSG), European Society of Pathology (ESP), and the Sociedade Portuguesa de EndoscopiaDigestiva (SPED). Endoscopy. 2012;44(1):74-94.

10. Pimentel-Nunes P, Libanio D, Marcos-Pinto R, Areia M, Leja M, Esposito G, et al. Management of epithelial precancerous conditions and lesions in the stomach (MAPS II): European Society of Gastrointestinal Endoscopy (ESGE), European Helicobacter and Microbiota Study Group (EHMSG), European Society of Pathology (ESP), and Sociedade Portuguesa de Endoscopia Digestiva (SPED) guideline update 2019. Endoscopy. 2019.

11. Banks M, Graham D, Jansen M, Gotoda T, Coda S, di Pietro M, et al. British Society of Gastroenterology guidelines on the diagnosis and management of patients at risk of gastric adenocarcinoma. Gut. 2019;68(9):1545-75.

12 Dixon MF, Genta RM, Yardley JH, Correa P. Classification and grading of gastritis. The updated Sydney System. International Workshop on the Histopathology of Gastritis, Houston 1994. Am J SurgPathol. 1996;20(10):1161-81.

13 Waddingham W, Graham D, Banks M, Jansen M. The evolving role of endoscopy in the diagnosis of premalignant gastric lesions. F1000Res. 2018;7:715.

14. den Hollander WJ, Holster IL, den Hoed CM, Capelle LG, Tang TJ, Anten MP, et al. Surveillance of premalignant gastric lesions: a multicentre prospective cohort study from low incidence regions. Gut. 2018;68(4):585-93.

15. Hassan C, Quintero E, Dumonceau JM, Regula J, Brandão C, Chaussade $\mathrm{S}$, et al. Post-polypectomy colonoscopy surveillance: European Society of Gastrointestinal Endoscopy (ESGE) Guideline. Endoscopy. 2013;45(10):842-51.

16. Ren W, Yu J, Zhang ZM, Song YK, Li YH, Wang L. Missed diagnosis of early gastric cancer or high-grade intraepithelial neoplasia. World J Gastroenterol. 2013;19(13):2092-6.

17. Menon S, Trudgill N. How commonly is upper gastrointestinal cancer missed at endoscopy? A meta-analysis. EndoscInt Open. 2014;2(2):E46-50.

18. Eshmuratov A, Nah JC, Kim N, Lee HS, Lee HE, Lee BH, et al. The correlation of endoscopic and histological diagnosis of gastric atrophy. Dig Dis Sci. 2010;55(5):1364-75.

19. Carpenter HA, Talley NJ. Gastroscopy is incomplete without biopsy: clinical relevance of distinguishing gastropathy from gastritis. Gastroenterology. 1995;108(3):917-24.

20. Anagnostopoulos GK, Yao K, Kaye P, Fogden E, Fortun P, Shonde A, et al. High-resolution magnification endoscopy can reliably identify normal gastric mucosa, Helicobacter pylori-associated gastritis, and gastric atrophy. Endoscopy. 2007;39(3):202-7.

21. Panteris V, Nikolopoulou S, Lountou A, Triantafillidis JK. Diagnostic capabilities of high-definition white light endoscopy for the diagnosis of gastric intestinal metaplasia and correlation with histologic and clinical data. Eur J GastroenterolHepatol. 2014;26(6):594-601.

22. Pimentel-Nunes P, Libanio D, Lage J, Abrantes D, Coimbra M, Esposito G, et al. A multicenter prospective study of the real-time use of narrow-band imaging in the diagnosis of premalignant gastric conditions and lesions. Endoscopy. 2016;48(8):723-30.

23. Kikuste I, Marques-Pereira R, Monteiro-Soares M, PimentelNunes P, Areia M, Leja M, et al. Systematic review of the diagnosis of gastric premalignant conditions and neoplasia with high-resolution endoscopic technologies. Scand J Gastroenterol. 2013;48(10):1108-17.

24. Doorakkers E, Lagergren J, Engstrand L, Brusselaers N. Helicobacter pylori eradication treatment and the risk of gastric adenocarcinoma in a Western population. Gut. 2018;67(12):2092-6.

25. Hwang YJ, Kim N, Lee HS, Lee JB, Choi YJ, Yoon H, et al. Reversibility of atrophic gastritis and intestinal metaplasia after Helicobacter pylori eradication - a prospective study for up to 10 years. Aliment PharmacolTher. 2018;47(3):380-90.

26. Zhang LJ, Wang SY, Huo XH, Zhu ZL, Chu JK, Ma JC, et al. Anti-Helicobacter pylori therapy followed by celecoxib on progression of gastric precancerous lesions. World J Gastroenterol. 2009;15(22):2731-8.

27. Hung KH, Yang HB, Cheng HC, Wu JJ, Sheu BS. Short-term celecoxib to regress long-term persistent gastric intestinal 
metaplasia after Helicobacter pylori eradication. J GastroenterolHepatol. 2010;25(1):48-53.

28. Ford AC, Forman D, Hunt RH, Yuan Y, Moayyedi P. Helicobacter pylori eradication therapy to prevent gastric cancer in healthy asymptomatic infected individuals: systematic review and metaanalysis of randomised controlled trials. BMJ. 2014;348:g3174.

29. Wang J, Xu L, Shi R, Huang X, Li SW, Huang Z, et al. Gastric atrophy and intestinal metaplasia before and after Helicobacter pylori eradication: a meta-analysis. Digestion. 2011;83(4):253-60.

30. Rokkas T, Sechopoulos P, Pistiolas D, Margantinis G, Koukoulis G. Helicobacter pylori infection and gastric histology in first-degree relatives of gastric cancer patients: a meta-analysis. Eur J GastroenterolHepatol. 2010;22(9):1128-33.

31. Capelle LG, de Vries AC, Haringsma J, Ter Borg F, de Vries RA, Bruno MJ, et al. The staging of gastritis with the OLGA system by using intestinal metaplasia as an accurate alternative for atrophic gastritis. GastrointestEndosc. 2010;71(7):1150-8.

Publisher's Note Springer Nature remains neutral with regard to jurisdictional claims in published maps and institutional affiliations.

\section{Ailiations}

\section{Michiel C. Mommersteeg ${ }^{1}$ - Stella A. V. Nieuwenburg ${ }^{1} \cdot$ Wouter J. den Hollander $^{2} \cdot$ Lisanne Holster $^{1}$. Caroline M. den Hoed ${ }^{1} \cdot$ Lisette G. Capelle ${ }^{3} \cdot$ Tjon J. Tang $^{4} \cdot$ Marie- Paule Anten $^{5} \cdot$ Ingrid Prytz-Berset $^{6}$. Ellen M. Witteman ${ }^{7}$. Frank ter Borg ${ }^{8}$. Jordy P. W. Burger ${ }^{9} \cdot$ Michail Doukas $^{10} \cdot$ Marco J. Bruno $^{1}$. Maikel P. Peppelenbosch ${ }^{1}$. Gwenny M. Fuhler ${ }^{1}$. Ernst J. Kuipers ${ }^{1} \cdot$ Manon C. W. Spaander $^{1} \mathbb{C}$}

1 Department of Gastroenterology and Hepatology, Erasmus University Medical Centre, Rotterdam, The Netherlands

2 Department of Gastroentroenterology and Hepatology, Leiden University Medical Centre, Leiden, The Netherlands

3 Department of Gastroentroenterology and Hepatology, Meander Medical Centre, Amersfoort, The Netherlands

4 Department of Gastroentroenterology and Hepatology, IJsselland Hospital, Capelle Aan Den IJssel, The Netherlands

5 Department of Gastroentroenterology and Hepatology, Sint Franciscus Hospital, Rotterdam, The Netherlands
6 Department of Gastroentroenterology and Hepatology, More and Romsdal Trust Ålesund, Ålesund, Norway

7 Department of Gastroentroenterology and Hepatology, Canisius-Wilhelmina Hospital, Nijmegen, The Netherlands

8 Department of Gastroentroenterology and Hepatology, Deventer Hospital, Deventer, The Netherlands

9 Department of Gastroenterology and Hepatology, Rijnstate, Arnhem, The Netherlands

10 Department of Pathology, Erasmus University Medical Centre, Rotterdam, The Netherlands 